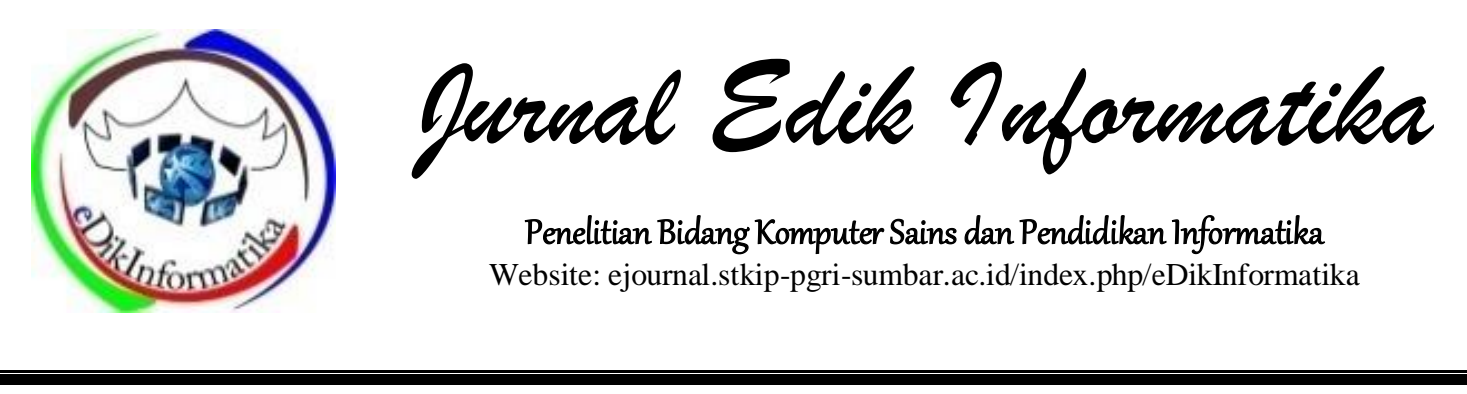

\title{
PERANCANGAN SISTEM INFORMASI ADMINISTRASI PEMBAYARAN SPP SISWA BERBASIS WEB
}

\author{
Yusran $^{1}$, Wulan Andang Purnomo ${ }^{2}$, Lido Sabda Lesmana ${ }^{3}$, Raimon Efendi ${ }^{4}$ \\ 1,2,3,4 Universitas Dharmas Indonesia \\ yusran@undhari.ac.id
}

INFO ARTIKEL

\section{Diterima:}

24 Maret 2020

Direview:

16 April 2020

Disetujui:

29 April 2020

\section{Keywords:}

SPP, Aplikasi, Java, MariaDB

\begin{abstract}
The development of technology and the development of science triggered many people to look for alternative solutions to problems in the field of information systems technology. Information technology is currently a very important requirement for the organization or company. Information technology has been widely used for various aspects such as management and human resources. Tuition payments are needed by madrasah to support educational needs, the current system is still done manually, madrasah treasurers record students who will pay tuition fees in books. Therefore researchers use the design of the MA Baiturrahaman Contribution of Education Development payment application to support the performance of the madrasah treasurer to conduct transactions quickly, and do not need to multiply work to process transactions and Contribution of Education Development payment report. The SPP payment application is designed with several stages ranging from data collection to system testing. The application design is designed using UML and developed with the java programming language and MariaDB as a database. The results of this study the treasurer can easily make payment transactions and SPP payment reports can be resolved properly.
\end{abstract}

\section{PENDAHULUAN}

Perkembangan teknologi dan perkembangan ilmu pengetahuan memicu banyak kalangan untuk mencari alternatif pemecahan masalah dibidang teknologi sistem informasi. Teknologi informasi saat ini merupakan kebutuhan yang sangat penting bagi organisasi atau perusahaan. Teknologi informasi telah banyak digunakan untuk berbagai aspek seperti manajamen dan sumber daya manusia. Salah satu contoh TI yang digunakan dalam aspek manajemen yaitu proses administratif pembayaran SPP 
dan iuran sekolah. Peningkatan mutu pelayanan pendidikan pada proses administrasi, salah satunya dalam bentuk sistem pembayaran Sumbangan Pembinaan Pendidikan (SPP) dibutuhkan kecepatan dan ketepatan pelayanan serta pengolahan data efektif. Madrasah Aliyah (MA) Baiturrahman Pulau Batu Kecamatan Jujuhan Ilir Provinsi Jambi saat ini dalam pelaksanaan kegiatan pembayaran iuran SPP masih dilakukan secara manual dimana setiap proses pembayaran siswa yang akan membayar iuran SPP membawa kartu pembayaran SPP, kemudian memberikan ke bendahara, selesai transaksi pembayaran iuran bendahara memberikan stempel dan paraf pada kartu pembayaran SPP siswa, kemudian bendahara akan melakukan pencatatan seluruh transaksi pembayaran iuran SPP kedalam buku yang telah ditentukan, pada akhir semester bendahara melakukan rekapitulasi seluruh iuran SPP yang telah dibayar oleh siswa untuk dibuatkan laporan ke kepala sekolah madrasah.

Kegiatan yang telah berlangsung pada MA Baiturrahman Kecamatan Jujuhan Ilir Provinsi Jambi selama ini sangatlah beresiko baik dalam kehilangan data, kerugian yang akan di alami oleh siswa serta proses kegiatan membutuhkan waktu yang lama dalam membuat rekap seluruh iuran yang masuk ditambah lagi setiap tahun jumlah siswa MA Baiturrahman terus meningkat. Untuk mengatasi permasalahan yang mungkin terjadi maka dibutuhkanlah suatu perubahan sistem aplikasi yang handal untuk memberikan efisiensi waktu serta ketepatan dalam pengolahan data yang akurat.

Pembayaran adalah pelunasan utang oleh debitur kepada kreditur bisa dilakukan dalam bentuk uang atau barang (Rochman et al., 2018). Dengan aplikasi yang akan dikembangkan bendahara MA Baiturrahman disediakan beberapa fitur yang user friendly sehingga mudah digunakan dalam mengisi data dan merekapitulasi seluruh iuran pembayaran SPP siswa MA serta dalam pembuatan laporan keuangan. Aplikasi ini juga memberikan kemudahan dalam mencek seluruh history pembayaran iuran SPP, dimana hasilnya dapat mencari dan melihat siswa yang sudah melakukan pembayaran atau yang belum. Dengan penggunaan aplikasi ini nantinya hasil setiap proses pengolahan data sangat membatu pihak sekolah dalam mendapatkan informasi iuran SPP yang akurat dan tepat waktu serta terjamin dari kehilangan data.

\section{METODE}

Dalam penyusunan penelitian ini, metodologi yang digunakan adalah metode deskriptif, yang menurut Sugiono (2011) adalah penelitian yang menggambarkan variabel yang berperan dalam memberikan situasi atau keadaan, serta menggambarkan hubungan yang ada pada variabel tersebut. Metode penelitian ini kemudian dibagi ke dalam dua teknik yaitu teknik pengumpulan data dan teknik pengembangan sistem, terdapat beberapa tahapan yang dilakukan, yang meliputi:

\section{Teknik Pengumpulan Data}

Teknik pengumpulan data dalam penulisan penelitian ini dilakukan dengan dua cara yaitu observasi dan studi pustaka.

\section{Teknik Pengembangan Sistem}

Metodologi yang digunakan adalah metode pengembangan sistem SDLC (System Development Life Cycle) dan analisis deskriptif, yaitu suatu metode penelitian yang bertujuan untuk 
menggambarkan suatu keadaan yang ada di perusahaan. Dalam pengembangan sistem informasi perlu digunakan metodologi sebagai pedoman bagaimana dan apa yang harus dilakukan selama melaksanakan pengembangan sistem.

Adapun pengembangan sistem yang digunakan adalah metodologi Water Fall Model. Adapun tahapantahapannya adalah sebagai berikut:

1. Software Enginering adalah suatu usaha untuk mentahapkan proses rekayasa perangkat lunak.

2. Analisis adalah kegiatan di dalam mengidentifikasi berbagai kebutuhan perangkat lunak untuk menentukan spesifikasi fungsi sistem, kinerja sistem dan kendala sistem.

3. Design, tahapan ini merupakan tahapan penerjemahan dari keperluan atau data yang telah dianalisis ke dalam bentuk yang lebih mudah dimengerti oleh pengguna.

4. Coding, implementasi dari desain yang menjadi bentuk yang dimengerti oleh mesin komputer.

5. Testing, pengetesan memfokuskan pada logika internal dari perangkat lunak, fungsi internal dan mencari segala kemungkinan kesalahan serta memeriksa apakah sesuai dengan hasil yang diharapkan.

6. Maintenance, penerapan secara keseluruhan disertai pemeliharaan jika terjadi perubahan struktur baik dari segi software.

\section{Rancangan Global}

Rancangan global merupakan gambaran umum tentang sistem. Rancangan ini merupakan persiapan dari rancangan terinci yang mengidentifikasikan komponen kompenen yang akan dirancang secara rinci. Sehingga hasil sistem yang dibuat mudah untuk digunakan oleh bendahara
MA Baiturrahaman. Unified Modelling Language (UML) adalah sebuah "bahasa" yang telah menjadi standar dalam industri untuk visualisasi, merancang dan mendokumentasikan sistem piranti lunak (Sulistyorini, 2009).

\section{Use Case Diagram}

Use case diagram digunakan untuk menggambarkan interaksi antara actor dan use case pada sistem perangkat lunak yang akan dikembangkan (Herliana \& Rasyid, 2016). Dalam use case yang disajikan berikut ini, terdapat empat proses utama yang dilakukan dalam sistem informasi monitoring yang akan dibuat. Secara lebih jelas, use case diagram dari program usulan dijelaskan dalam Gambar 1.

Dari use case diagram pada Gambar 1 dapat dilihat bahwa actor yang berada dalam sistem adalah bendahara, sedangkan siswa berada diluar sistem atau biasa disebut orang yang tidak menggunakan sistem namun ada keterlibatannya dalam sistem tersebut.

\section{Activity Diagram}

Activity diagram memodelkan alur kerja (workflow) sebuah proses bisnis dan urutan aktivitas dalam suatu proses (Herliana \& Rasyid, 2016). Diagram ini sangat mirip dengan sebuah flowchart karena dapat dimodelkan sebuah alur kerja dari satu aktivitas ke aktivitas lainnya atau dari satu aktivitas ke dalam keadaan sesaat (state). Secara lebih jelas, activity diagram login dari program usulan dijelaskan dalam Gambar 2.

Dari activity diagram login pada Gambar 2 terlihat sistem menampilkan halaman login bendahara, kemudian bendahara mengisi form login, selanjutnya sistem akan menampilkan halaman menu utama, jika username dan password salah akan kembali ke menu login. 


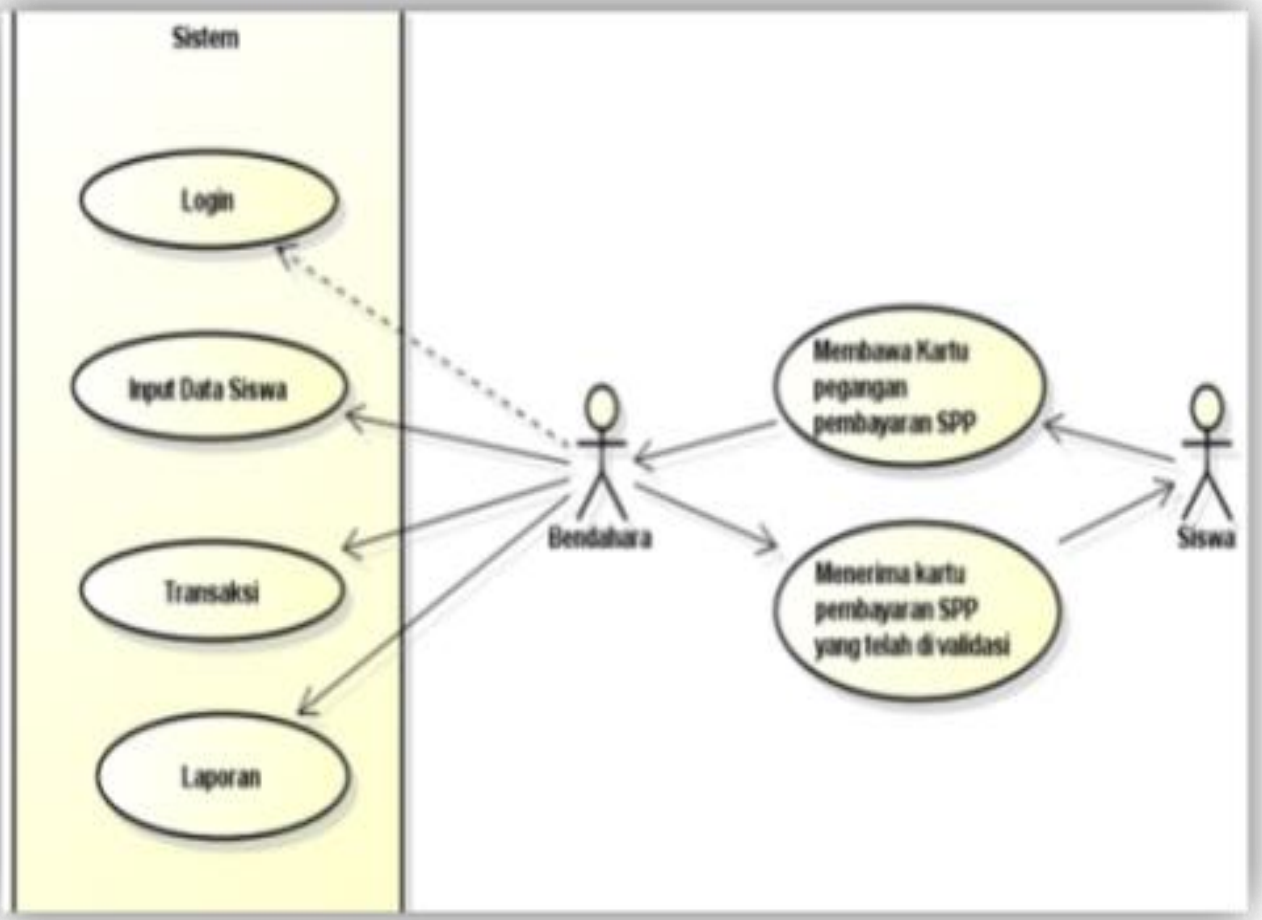

Gambar 1. Use Case Diagram

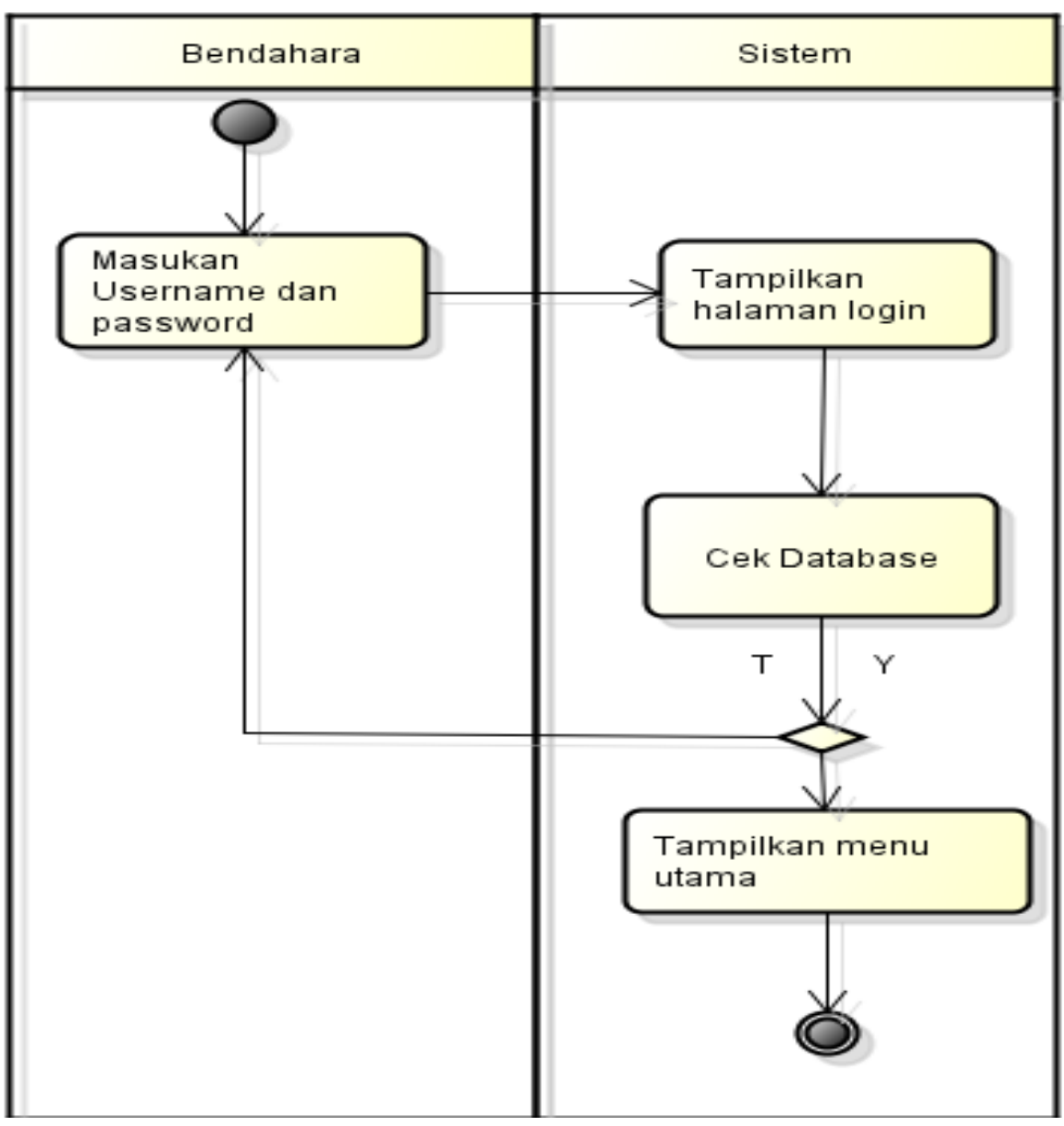

Gambar 2. Activity Diagram Login 


\section{Scenario Diagram}

Tabel 1. Keterangan Use Case

\begin{tabular}{ll}
\hline \multicolumn{1}{c}{ Atribut } & \multicolumn{1}{c}{ Keterangan } \\
\hline Nama Use Case & Login \\
Aktor & Bendahara \\
Tujuan & Untuk login Bendahara \\
Deskripsi & Proses ini dilakukan agar Bendahara dapat \\
\hline
\end{tabular}

Tabel 2. Scenario

\begin{tabular}{|c|c|c|}
\hline Skenario & Aksi Aktor & Reaksi Sistem \\
\hline Skenario Awal & & Form utama ditampilkan \\
\hline & Buka menu login & Form login ditampilkan \\
\hline Skenario Proses & $\begin{array}{l}\text { Masukkan username } \\
\text { dan password }\end{array}$ & $\begin{array}{l}\text { Jika password benar akan masuk } \\
\text { ke halaman selanjutnya, jika salah } \\
\text { akan kembali ke form login }\end{array}$ \\
\hline Skenario Akhir & & Halaman selanjutnya ditampilkan \\
\hline
\end{tabular}

\section{HASIL DAN PEMBAHASAN}

Setelah menganalisis sistem yang berjalan di MA Baiturrahman Kecamatan Jujuhan Ilir, terdapat banyak kekurangan dalam proses administrasi pembayaran SPP siswa. Maka selanjutnya akan dibahas mengenai rancangan usulan sistem yang akan dibangun. Rancangan prosedur yang diusulkan bertujuan untuk menyempurnakan dan memberikan alternatif dalam memberikan informasi juga mempermudah bagian bendahara dalam penginputan data secara terkomputerisasi, memudahkan penanganan antrian ketika siswa melakukan pembayaran SPP, yang dapat diakses dimanapun dan kapanpun, serta memudahkan dalam pembuatan hasil laporan. Perbedaan sistem yang berjalan dengan sistem yang diusulkan semoga akan membawa dampak positif bagi pihak yang menggunakannya, supaya dalam pelaksanaannya pembayaran SPP bisa lebih efektif dan efisien waktu dan biaya.

\section{Tampilan Halaman Login}

Tampilan halaman login ini untuk bendahara sebagai sistem keamanan pada saat menjalankan sistem. Sesuai dengan skenario pada Tabel 1 dan Tabel 2, bendahara harus mengisi username dan password agar bisa masuk ke aplikasi selanjutnya menekan tombol login. Fungsi utama dari halaman login adalah untuk melindungi keamanan sistem dan database. Tampilan halaman login dapat dilihat pada Gambar 3.

\section{Tampilan Form Data Siswa}

Form siswa berfungsi jika bendahara ingin menambah data siswa, mengedit dan menghapus dengan cara menekan tombol simpan, tombol edit dan hapus. Tampilan form data siswa dapat dilihat pada Gambar 4. 


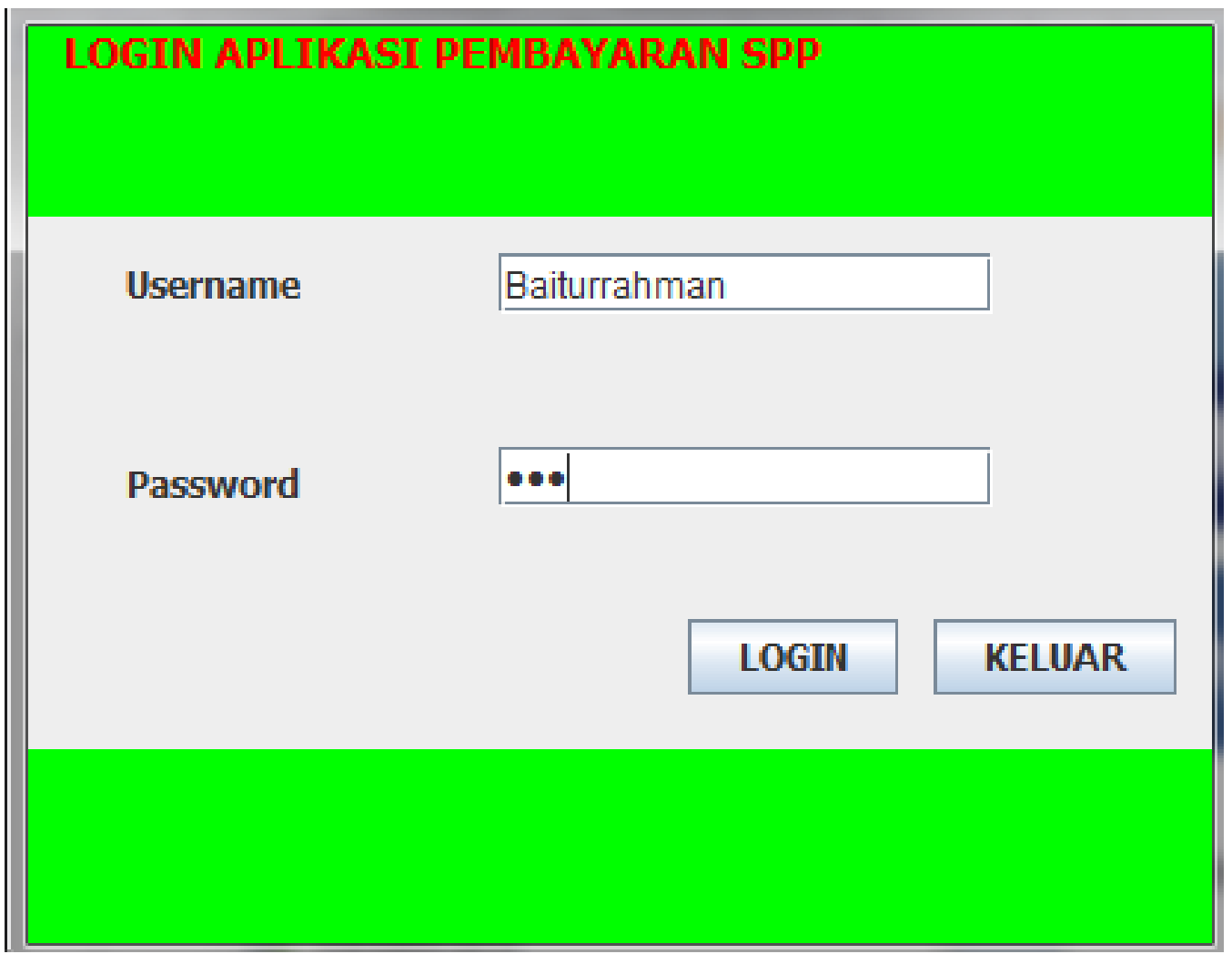

Gambar 3. Tampilan Halaman Login

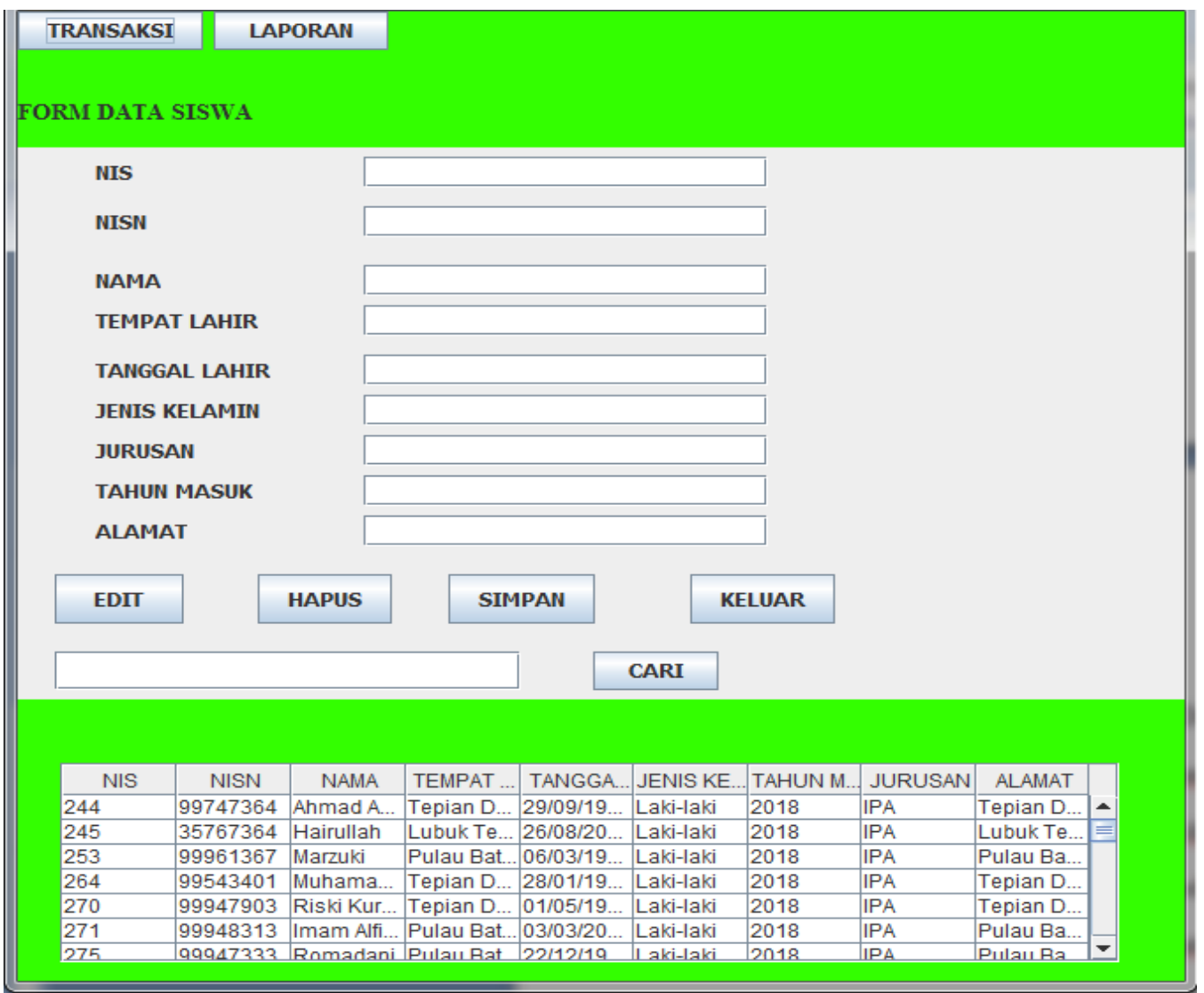

Gambar 4. Tampilan Form Data Siswa 


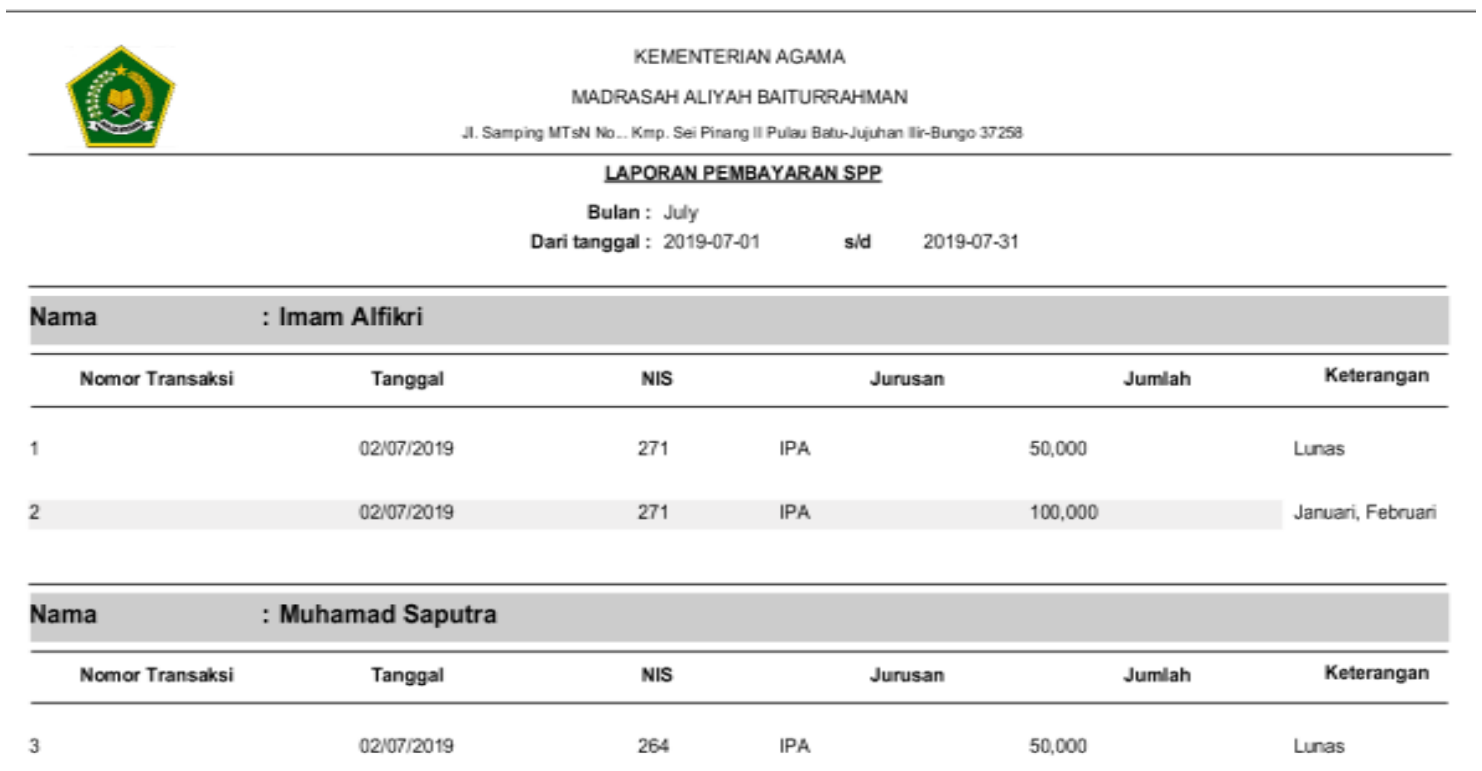

Gambar 5. Tampilan Bulanan Pembayaran SPP

\section{Tampilan Bulanan Pembayaran SPP}

Form tampilan bulanan ini sebagai bukti dan laporan bagi sekolah untuk mengetahui data-data siswa yang sudah melakukan dan yang belum melakukan pembayaran iuran SPP. Tampilan bulanan pembayaran SPP dapat dilihat pada Gambar 5.

\section{KESIMPULAN}

Pembayaran SPP merupakan sebuah dasar bagi perkembangan sebuah sekolah yang dapat membantu sistem tata kerja yang baik. Oleh karena itu dibutuhkan sebuah sistem yang dapat menunjang bagi pengolahan pembayaran SPP agar bisa memudahkan pihak sekolah terutama bagian tata usaha dalam mengelola informasi yang ada. Dengan adanya sistem pembayaran SPP terotomatisasi seperti ini maka proses pengolahan data akan menjadi lebih cepat, tepat dan efisien. Pihak sekolah akan merasa terbantu dalam proses pengerjaan tugasnya, pihak orang tua murid juga akan merasakan kemudahan dalam mendapatkan informasi yang akurat dari pihak sekolah sehingga dapat mengurangi keterlambatan.

\section{DAFTAR PUSTAKA}

Abdurahman, H., Riswaya, A. R., \& Id, A. (2014). Aplikasi Pinjaman Pembayaran Secara Kredit Pada Bank Yudha BHakti. Aplikasi Pinjaman Pembayaran Secara Kredit Pada Bank Yudha BHakti, 8(2), 61-69. http://jurnal.stmikmi.ac.id/index.php/jcb/article/view/ $114 / 138$

Herliana, A., \& Rasyid, P. M. (2016). Sistem Informasi Monitoring Perkembangan Software pada tahap Development Berbasi Web. 1, 41-50.

Rochman, A., Sidik, A., \& Nazahah, N. (2018). Perancangan Sistem Informasi Administrasi Pembayaran SPP Siswa Berbasis Web di SMK Al-Amanah. Jurnal Sisfotek Global, $8(1)$, 51-56. https://doi.org/10.1002/ijc.23959

Sulistyorini, P. (2009). Pemodelan Visual dengan Menggunakan UML dan Rational Rose. Jurnal Teknologi Informasi DINAMIK Volume, XIV(1), 23-29. 